Document downloaded from:

http://hdl.handle.net/10251/68518

This paper must be cited as:

Pretel, R.; Durán Pinzón, F.; Robles Martínez, A.; Ruano García, MV.; Ribes Bertomeu, J.; Serralta Sevilla, J.; Ferrer, J. (2015). Designing an AnMBR-based WWTP for energy recovery from urban wastewater: The role of primary settling and anaerobic digestion. Separation and Purification Technology. 156:132-139. doi:10.1016/j.seppur.2015.09.047.

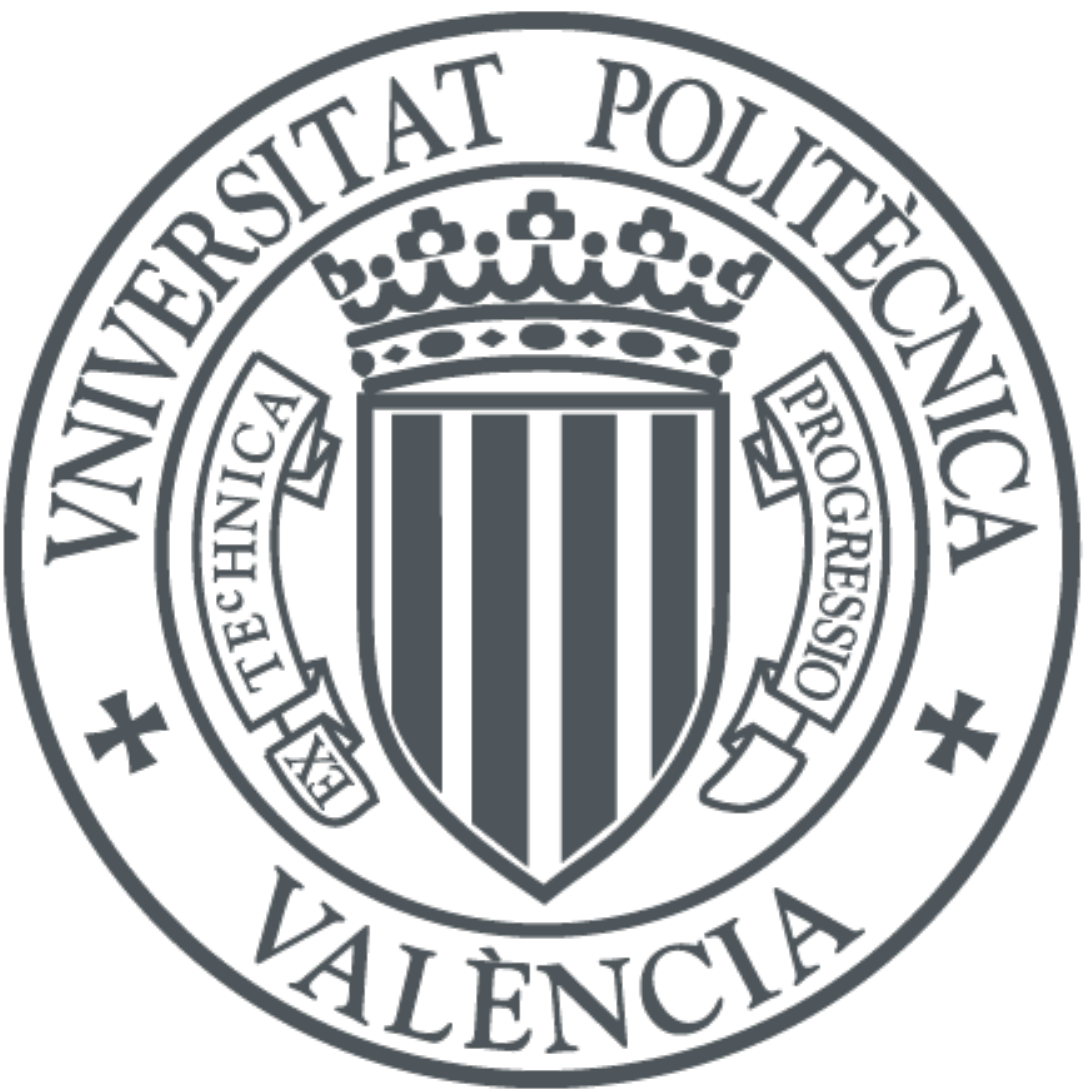

The final publication is available at

http://dx.doi.org/10.1016/j.seppur.2015.09.047

Copyright Elsevier

Additional Information 


\title{
Designing an AnMBR-based WWTP for energy recovery from urban wastewater: the role of primary settling and anaerobic \\ digestion
}

\author{
R. Pretel ${ }^{\mathrm{a}, *}$, F. Durán ${ }^{\mathrm{a}}$, A. Robles ${ }^{\mathrm{a}}$, M.V. Ruano ${ }^{\mathrm{b}}$, \\ J. Ribes ${ }^{\mathrm{b}}$, J. Serralta ${ }^{\mathrm{a}}$, and J. Ferrer ${ }^{\mathrm{a}}$ \\ a Institut Universitari d'Investigació d'Enginyeria de l'Aigua i Medi Ambient, IIAMA, \\ Universitat Politècnica de València, Camí de Vera s/n, 46022 Valencia, Spain (e-mail:; \\ rutprejo@upv.es; fredurpi@upv.es; ngerobma@upv.es; jserralt@hma.upv.es, \\ jferrer@hma.upv.es) \\ b Departament d'Enginyeria Química, Escola Tècnica Superior d'Enginyeria, Universitat de \\ València, Avinguda de la Universitat s/n, 46100 Burjassot, Valencia, Spain (e-mail: \\ m.victoria.ruano@uv.es; josep.ribes@uv.es) \\ * Corresponding author: tel. +34 9638799 61, e-mail: rutprejo@upv.es
}

\begin{abstract}
The main objective of this paper is to assess different treatment schemes for designing a submerged anaerobic membrane bioreactor (AnMBR) based WWTP. The economic impact of including a primary settling (PS) stage and further anaerobic digestion (AD) of the wasted sludge has been evaluated. The following operating scenarios were considered: sulphate-rich and low-sulphate urban wastewater (UWW) treatment at 15 and $30{ }^{\circ} \mathrm{C}$. To this aim, the optimum combination of design/operating parameters that resulted in minimum total cost (CAPEX plus OPEX) for the different schemes and scenarios was determined. The AnMBR design was based on both simulation and experimental results from an AnMBR plant featuring industrial-scale hollow-fibre membranes fed with UWW from the pre-treatment of a municipal WWTP located in Valencia (Spain). AnMBR without PS and AD was identified as the most economic option for an AnMBRbased WWTP treating low-sulphate UWW (minimum cost of $€ 0.05$ per $\mathrm{m}^{3}$ and a maximum surplus energy of $0.1 \mathrm{kWh}$ per $\mathrm{m}^{3}$ ), whilst AnMBR with PS and AD was
\end{abstract}


the optimum option when treating sulphate-rich UWW (minimum cost of $€ 0.05$ per

$\mathrm{m}^{3}$ and a maximum surplus energy of $0.09 \mathrm{kWh}$ per $\mathrm{m}^{3}$ ).

\section{Keywords}

CAPEX/OPEX; full-scale design; industrial-scale hollow-fibre membranes; submerged anaerobic MBR (AnMBR); urban wastewater treatment

\section{Introduction}

In recent years, urban wastewater (UWW) is being looked at more as a resource than as a waste, a renewable source potential of energy, water and nutrients [1]. In this respect, anaerobic membrane bioreactors (AnMBR) technology has been reported as an emerging technology for sustainable low-strength wastewater treatment (e.g. UWW) rather than traditional aerobic wastewater treatment (see, for instance, $[2 ; 3 ; 4]$ ).

On the one hand, as an anaerobic process this technology presents: i) low sludge production because of the low yield of anaerobic microorganisms; ii) low energy consumption because no aeration is required; and iii) potential resource recovery because energy (from biogas production) and nutrients $\left(\mathrm{NH}_{4}{ }^{+}\right.$and $\left.\mathrm{PO}_{4}{ }^{3-}\right)$ can be obtained from the anaerobic degradation process. Indeed, complete anaerobic treatment of UWW has the potential to achieve net energy production while meeting stringent effluent standards [1]. Moreover, AnMBR technology may produce more net energy and had lower life cycle environmental emissions than conventional UWW treatment processes [5].

On the other hand, the treatment capacity of membrane bioreactors (MBR) has increased significantly, enabling them to be used even in large municipal wastewater 
treatment plants (WWTPs). However, WWTPs fitted with MBRs use aerobic processes which require considerable aeration in order to remove organic matter, apart from the required air to scour the membrane surface.

As regards the biological treatment of UWW, the low influent COD (typically less than $1 \mathrm{~g} \cdot \mathrm{L}^{-1}$ ) results in low methane productions. Therefore, an external energy source is usually needed to heat the reactor to mesophilic conditions [6]. According to Martín et al. [7], if the influent wastewater temperature is around $15^{\circ} \mathrm{C}$, then COD levels must be higher than $4-5 \mathrm{~g} \cdot \mathrm{L}^{-1}$ in order to generate enough biogas to heat the reactor to $35^{\circ} \mathrm{C}$. Hence, the only economically feasible option for the anaerobic treatment of UWW is to operate at ambient temperature conditions. AnMBR technology allows treating UWW at ambient temperature because hydraulic retention time (HRT) and sludge retention time (SRT) are decoupled due to the filtration process. AnMBR can be operated at high SRT without requiring high anaerobic reactor volumes.

The main biological operating parameters in AnMBR systems are SRT, organic loading rate (OLR) and temperature which finally determine, among others, the use of the wastewater's energy potential. Among the different schemes that can be found in literature, AnMBR based-technology could be proposed as itself or with primary settling and further anaerobic digestion of the wasted sludge [1]. When ambient temperature is not so high, including a previous settling step and anaerobic digestion in the AnMBR based-scheme could reduce the reactor volume required to achieve the same methane production. Due to the high COD in primary and wasted sludge, anaerobic digestion can be operated at $35^{\circ} \mathrm{C}$ using the biogas produced. Therefore, the SRT required in the anaerobic digestion will be lower than in the AnMBR system. 
As regards the filtration process, one key challenge for sustainable full-scale AnMBR operation consists in achieving proper membrane performances under minimum operating cost whilst minimising membrane fouling, particularly irrecoverable/permanent fouling that cannot be removed by chemical cleaning. The extent of irrecoverable/permanent fouling is what ultimately determines the membrane lifespan (see, for instance, $[4 ; 8]$ ). It is therefore necessary to optimise filtration whilst minimising not only capital expenditure (CAPEX) but also operating and maintenance expenditure (OPEX). Gas sparging intensity, usually measured as the specific gas demand per permeate volume (SGDP) or as the specific gas demand per membrane area $\left(\mathrm{SGD}_{\mathrm{m}}\right)$, is considered a key operating parameter to maximise energy savings in AnMBRs (see, for instance, $[9 ; 10])$.

In this study we have evaluated the total cost of the following treatment schemes: AnMBR, AnMBR + anaerobic digester (AD), primary settler (PS) + AnMBR + AD for different operating scenarios: sulphate-rich and low-sulphate UWW treatment at 15 and $30{ }^{\circ} \mathrm{C}$. To select the most appropriate treatment scheme for each scenario, the optimum combination of design/operating parameter values that resulted in minimum cost was determined for each AnMBR WWTP scheme. The AnMBR design was based on both simulation and experimental results from an AnMBR plant featuring industrial-scale hollow-fibre membranes that was fed with UWW from the pre-treatment of a municipal WWTP located in Valencia (Spain).

\section{Materials and methods}

As mentioned earlier, this study establishes the optimum design for AnMBR WWTPs for UWW treatment with and without primary settling and further anaerobic 
digestion of the wasted sludge. To this aim, the design methodology proposed by Ferrer et al. [11] was used. This methodology is based on both simulation and experimental results. Experimental data were obtained from an AnMBR plant fitted with industrialscale membranes that was fed with UWW. Simulation results were obtained using the WWTP simulating software DESASS [12] which enables a wide range of wastewater treatment schemes (including AnMBR systems) to be evaluated.

\subsection{AnMBR plant description and operation}

The AnMBR plant consists of an anaerobic reactor with a total volume of $1.3 \mathrm{~m}^{3}$ connected to two membrane tanks, each with a total volume of $0.8 \mathrm{~m}^{3}$. Each membrane tank features one commercial ultrafiltration hollow-fibre membrane system (PURON®, Koch Membrane Systems, $0.05 \mu \mathrm{m}$ pore size, $30 \mathrm{~m}^{2}$ total filtering area, and outside-in filtration). As mentioned above, this plant was fed with UWW coming from the pretreatment of the Carraixet WWTP (Valencia, Spain), which involves screening, degritting and grease removal. Further details of this AnMBR can be found in Giménez et al. [13].

This AnMBR plant was run for more than 5 years under different operating conditions (see, for instance, $[14 ; 15]$ ). Regarding the biological process, the plant was operated at sludge retention times ranging from 20 to 70 days, with controlled HRT

ranging from 5 to 30 hours, and OLR ranging from 0.5 to $2 \mathrm{~kg} \mathrm{COD} \cdot \mathrm{m}^{3} \cdot \mathrm{d}^{-1}$. The impact of temperature on process performance was evaluated in the range of $14-33^{\circ} \mathrm{C}$. As regards filtration, the membranes were operated at $20^{\circ} \mathrm{C}$-standardised transmembrane fluxes $\left(J_{20}\right)$ ranging from 6 to 20 litres per square metre of membrane area per hour $(\mathrm{LMH})$ and $\mathrm{SGD}_{\mathrm{m}}$ from 0.05 to $0.5 \mathrm{~m}^{3} \cdot \mathrm{m}^{-2} \cdot \mathrm{h}^{-1}$. The mixed liquor suspended solids 
(MLSS) concentration ranged from around 5 to $30 \mathrm{~g} \cdot \mathrm{L}^{-1}$.

\subsection{AnMBR WWTP simulation}

Figure 1 illustrates a flow diagram of the different treatment schemes to be assessed. As Figure 1 shows, all the schemes include the following common units: 1) a pre-treatment unit; 2) a clean-in-place tank; 3) a degassing membrane for capturing the dissolved methane in the effluent; 4) a combined heat and power (CHP) system enabling energy to be recovered from methane; and 5) a dewatering system for conditioning the resulting sludge.

The three different treatment schemes considered in this study for designing an AnMBR WWTP are (see Figure 1): a) AnMBR; b) AnMBR + AD fed with the sludge coming from the AnMBR; c) PS + AnMBR + AD fed with the sludge coming from both PS and AnMBR. However, the last treatment scheme was modified when low-sulphate UWW was treated. As it will be shown in the results section the SRT in the AnMBR required to fulfil the effluent criteria was high enough to meet sludge stabilisation criteria. Pumping the wasted sludge to the anaerobic digester leads to a significant increase in its volume but an almost negligible increase in the methane production. Therefore, it was decided to feed the anaerobic digester only with primary sludge. In addition, the variation of total cost due to including a sludge thickener in treatment schemes with AD has also been estimated.

As previously commented, the proposed AnMBR WWTP was simulated using a new version of DESASS [12]. This simulating software features a modified version of the mathematical model BNRM2 [16] including the competition between both 
acidogenic and methanogenic microorganisms and sulphate-reducing microorganisms [17]. In other words, sulphate reduction to sulphide and stripping of hydrogen sulphide from the liquid phase were considered in the extended version of BNRM2. The mathematical model (BNRM2) built into DESASS was validated beforehand using experimental data obtained from the AnMBR plant [17].

The influent wastewater pattern proposed in the Benchmark Simulation Model n.1 [18] was used in this study. Therefore, the proposed AnMBR WWTP was designed to handle an influent flow of $18,446 \mathrm{~m}^{3} \cdot \mathrm{d}^{-1}$. The full characterisation of the UWW used in this study is shown in Table 1. The following four simulation scenarios were evaluated: the treatment at i) 15 and ii) $30^{\circ} \mathrm{C}$ of sulphate-rich UWW (3.8 $\mathrm{mg} \mathrm{COD} \cdot \mathrm{mg}^{-1} \mathrm{SO}_{4}-\mathrm{S}$, corresponding to an influent sulphate concentration of $100 \mathrm{mg} \mathrm{SO}_{4}$-S (i.e. $380 \mathrm{mg}$ $\mathrm{COD} / 100 \mathrm{mg} \mathrm{SO}_{4}-\mathrm{S}$ )); and the treatment at iii) 15 and iv) $30^{\circ} \mathrm{C}$ of low-sulphate UWW (38.1 $\mathrm{mg} \mathrm{COD} \cdot \mathrm{mg}^{-1} \mathrm{SO}_{4}-\mathrm{S}$, corresponding to an influent sulphate concentration of 10 $\mathrm{mg} \mathrm{SO} 4-\mathrm{S}$ (i.e. $380 \mathrm{mg} \mathrm{COD/10} \mathrm{mg} \mathrm{SO}_{4}-\mathrm{S}$ )).

\subsection{Design methodology}

The following terms were considered for OPEX calculation: rotofilter operation, membrane scouring by biogas sparging, mixing, sludge pumping, permeate pumping, chemical reagent consumption for membrane cleaning, replacing membranes at the end of membrane lifespan, equipment replacement, sludge settling, sludge thickening, sludge handling and disposal (including dewatering system and polyelectrolyte consumption), $\mathrm{AD}$ heating input energy, energy recovery from $\mathrm{AD}$ biogas, energy recovery from AnMBR biogas, and energy recovery from methane dissolved in the AnMBR effluent. On the other hand, the following terms were considered for CAPEX 
calculation: rotofilter, pumping equipment, piping system, stirrers, ultrafiltration hollow-fibre membranes, reinforced concrete structures, circular suction scraper bridges (primary settler and sludge thickener), sludge dewatering system (centrifuges) and land needed. The total cost of the technology needed for energy recovery (degassing membrane for capturing the methane dissolved in the effluent and microturbine-based CHP for energy recovery) was also considered.

\subsubsection{AnMBR design}

The methodology proposed by Ferrer et al. [11] was applied in this study for designing the AnMBR-based WWTP. According to this methodology, HRT, SRT and the level of suspended solids in the mixed liquor in the membrane tank $\left(M L S S_{M T}\right)$ are the key operating parameters when designing the biological process in AnMBR technology and $J_{20}, S G D_{m}$ and $M L S S_{M T}$ are the key operating parameters when designing the filtration process.

This design methodology aims to minimise total cost, and consists of two main stages. The first stage involves optimising two parameters related to the anaerobic reactor, i.e. anaerobic reactor volume $(V)$ and the sludge recycling flow rate from the membrane tank to the anaerobic reactor $\left(Q_{r e c}\right)$. At a given operating temperature and influent flow and load, the AnMBR performance is simulated at different SRT and $M L S S_{M T}$ (for $Q_{\text {rec }}=$ influent flow). The SRT values used in the simulations must be above the minimum SRT needed to meet effluent standards $\left(\mathrm{COD}<125 \mathrm{mg} \cdot \mathrm{L}^{-1}\right.$ and BOD $<25 \mathrm{mg} \cdot \mathrm{L}^{-1}$ ) and sludge stabilisation criteria (percentage of biodegradable volatile suspended solids (\%BVSS) $<35 \%)$ ). For the treatment schemes in which AnMBR technology is combined with AD or PS and AD the sludge stabilisation criteria was 
applied to the sludge wasted from the AD unit.

These simulation results are used to determine the optimum combination of anaerobic reactor volume and sludge recycling flow rate for each SRT and $M L S S_{M T}$. The optimum combination (V(opt), $\left.Q_{r e c}(o p t)\right)$ is the one that minimises the total cost for the biological process. Therefore, the minimum cost of the biological process is calculated for each SRT-MLSS $M T$ combination. This calculation also takes into account the costs of sludge handling and disposal, and the savings made by recovering energy from methane capture.

The second stage involves optimising the operating parameters $S G D_{m}$ and $J_{20}$ for the different $M L S S_{M T}$ levels evaluated in the simulations carried out to calculate the cost of the filtration process (see [19]). Before applying this methodology, the $20{ }^{\circ} \mathrm{C}$ standardised critical flux $\left(J_{C 20}\right)$ must be experimentally determined at different $M L S S_{M T}$ and $S G D_{m}$. Once $J_{C 20}$ has been experimentally obtained, the following variables are calculated for different $J_{20}$ values above and below $J_{C 20}$ : membrane tank volume, membrane filtration area $\left(A_{m}\right)$, biogas flow rate recycled into membrane tank $\left(Q_{G}\right)$, transmembrane pressure $(T M P)$, membrane permeability $(K)$ and the amount of chemical reagents required for chemical membrane cleaning according to the membrane manufacturer recommendations. These values are used to calculate the filtration cost, taking into account the following cost items: membrane area, membrane tank, biogas sparging, blowers and pipes, permeate pumping, chemical reagents and membrane replacement. Then, for each level of $M L S S_{M T}$ the optimum values of $J_{20}$ and $S G D_{m}$ are selected, i.e. the ones leading to the lowest filtration cost.

Further details of this AnMBR design methodology can be found in Ferrer et al. 
[11].

\subsubsection{Primary settler design}

As Figure 1 shows, one AnMBR-based WWTP treatment scheme including primary settling is considered in this study (see Figure 1c). HRT is the key operating parameter when designing the primary settling step. The required number of PSs was determined based on a maximum unit diameter of 30 meters. As a result, one unit was required for designing the primary settling step, resulting in a HRT value of around 3 hours.

\subsubsection{Anaerobic digester design}

As Figure 1 illustrates, two treatment schemes including an anaerobic digestion step for the sludge wasted from the AnMBR are considered in this study. As previously commented, the AD unit was initially fed with the sludge coming from both PS and AnMBR. However, the sludge wasted from the AnMBR when treating low-sulphate UWW was stabilised and it was not worth to pump it into the anaerobic digester.

The AD unit was simulated at different SRT (from 5 to 30 days) under mesophilic temperature conditions $\left(35^{\circ} \mathrm{C}\right)$. All the values selected for SRT were above the minimum SRT needed to meet the sludge stabilisation criteria $(\% \mathrm{BVSS}<35 \%)$. The cost of the AD unit was then calculated for each SRT taking into account the following cost items: construction of the digester including pumps and pipes, energy required for stirring and sludge pumping, savings made by recovering energy from methane capture, and the heat energy requirement to maintain the operating temperature. 


\subsubsection{Total annualised cost}

The total annualised cost of the different scenarios was calculated by adding the annualised capital expenditure to the annual operating and maintenance expenditure, as shown in Equation 1 [20]:

$$
T A C=\frac{\mathrm{r}(1+\mathrm{r})^{\mathrm{t}}}{(1+r)^{t}-1} \cdot C A P E X+O P E X
$$

Equation 1

where $r$ is the annual discount rate, and $t$ is the depreciation period in years.

CAPEX includes construction work (primary settler, anaerobic reactor, membrane tank, anaerobic digester, sludge thickener, and the corresponding required land) and equipment (pumps, blowers, pipes, membranes, stirrers, rotofilter, sludge dewatering system, microturbine-based CHP system, degassing membrane for recovering the methane dissolved in the effluent and circular suction scraper bridge (for primary settler and sludge thickener)). OPEX includes energy requirements (heat and power), energy recovery from methane capture (biogas methane and methane dissolved in the effluent), chemical reagents used to clean membranes, and sludge handling and disposal. Maintenance expenditure refers to pumps, blowers, stirrers, rotofilter and membrane replacement.

Further details on CAPEX/OPEX calculations in AnMBR, as well as the unit cost values used in this study, can be found in Ferrer et al. [11] and Pretel et al. [19]. In 
addition, the following considerations have been also taken into account when calculating CAPEX and OPEX in this work:

- For the sludge dewatering system, flow treatment of $55 \mathrm{~m}^{3} \cdot \mathrm{h}^{-1}$, power consumption of $45 \mathrm{kWh} \cdot \mathrm{t}^{-1} \mathrm{TSS}$ and $265 \mathrm{k} €$ of CAPEX have been considered.

- For the circular suction scraper bridge for primary settler and sludge thickener, power consumption of $0.75 \mathrm{~kW}$ and $245 \mathrm{k} €$ of CAPEX have been considered.

- According to the Ministry of Agriculture, Food and Environment [21], the following final disposal of the wasted sludge was considered in this study the: $80 \%$ to farmland (cost of $\left.4.81 € \cdot \mathrm{t}^{-1}\right), 10 \%$ to incineration (cost of 250 $€ \cdot \mathrm{t}^{-1}$ ) and $10 \%$ to landfilling (cost of $\left.30.05 € \cdot \mathrm{t}^{-1}\right)$.

\section{Results and discussion}

\subsection{Optimum design values}

Table 2 summarises the optimum design values for the AnMBR and AD units included in the different schemes proposed for designing an AnMBR-based WWTP treating low-sulphate and sulphate-rich UWW at 15 and $30^{\circ} \mathrm{C}$.

As Table 2a shows, the optimal SRT for the AnMBR unit when it is not combined with primary settling and further anaerobic digestion of the wasted sludge was lower when treating low-sulphate rather than sulphate-rich UWW. Specifically, the optimal SRT when operating at $15{ }^{\circ} \mathrm{C}$ resulted in 35 and 60 days when treating low-sulphate and 
sulphate-rich UWW, respectively, whilst when operating at $30{ }^{\circ} \mathrm{C}$ it resulted in 12 and 22 days, respectively. When sulphate-rich UWW is treated, the BOD is mainly biodegraded by sulphate-reducing bacteria (SRB). SRB have a biomass yield much higher than methanogenic archaea (MA) (see [17]). Therefore, the simulation results for this case study showed that the biomass production is much higher when treating sulphate-rich UWW and, consequently, a higher SRT is required for meeting the sludge stabilisation criteria (\%BVSS < 35\%). In addition, when treating sulphate-rich UWW no methane production was envisaged on the basis of the model since as abovementioned BOD is mainly biodegraded by SRB instead of by MA.

It is worth to point out that the optimum SRTs for sulphate-rich UWW corresponded with the minimum SRT required for meeting the sludge stabilisation criteria. However, the optimum SRTs for low-sulphate UWW corresponded with the minimum SRT required for meeting the European discharge quality standards for BOD.

In contrast with the results obtained in the AnMBR configuration, the optimal SRT for the AnMBR unit when it is combined with AD or PS and AD was lower when treating sulphate-rich UWW than when treating low-sulphate UWW (see Table 2a). In this case, shorter SRTs are required in the AnMBR unit since further degradation of the organic matter is conducted in the AD. Therefore, there is no minimum SRT limitation in the AnMBR unit as regards sludge stabilisation. Thus, the optimal SRT for the AnMBR corresponded with the minimum SRT required for meeting the European discharge quality standards for BOD. Hence, the optimal SRT for the AnMBR unit when treating low-sulphate UWW, which was already limited by the European discharge quality standards, could not be reduced when an additional anaerobic digestion step was included in the treatment scheme. 
Regarding the design of the AD unit in the AnMBR+AD and PS+AnMBR+AD configurations, Table $2 \mathrm{~b}$ shows that the optimal SRT for this element was higher when treating sulphate-rich rather than low-sulphate UWW. This is the consequence of the higher degree of sludge stabilisation reached in the AnMBR sludge when treating lowsulphate UWW

As regards the effect of temperature, Table 2 a shows that, as expected, increasing the operating temperature from 15 to $30^{\circ} \mathrm{C}$ results in a decrease of the optimum SRT. Hence, lower SRTs are required for meeting both sludge stabilisation criteria (\%BVSS $<35 \%)$ and effluent quality standards for BOD $\left(25 \mathrm{mg} \mathrm{BOD} \cdot \mathrm{L}^{-1}\right)$ when operating in warm climate areas.

With regard to including primary settling in the AnMBR-based configuration, as Table 2 illustrates, for the four scenarios considering PS allows reducing slightly the optimal SRT in the AnMBR unit, but increases the resulting SRT in the AD unit.

Concerning the rest of parameters included in Table 2, the corresponding optimal values are determined by minimising the resulting total cost for the different units included in the considered treatment schemes, as it has been described in Section 2.3. Variations on these parameters were mainly related to variations in SRT and MLSS (affected by the fate of the influent particulate organic matter). It is important to highlight that operating at low MLSS levels in the anaerobic reactor allows commonly reducing the optimal design values for the following parameters (see Table 2): $Q_{\text {rec }}$, which allows reducing sludge pumping cost; and $M L S S_{M T}$, which allows increasing $J_{20}$ thus reducing membrane scouring cost for a given $S G D_{m}$ due to the consequent 
membrane area reduction. In this respect the lowest design values for $Q_{r e c}$, HRT and $M L S S_{M T}$ correspond to the PS+AnMBR+AD scheme.

\subsection{AnMBR-based WWTP treating low-sulphate $U W W$}

\subsubsection{Minimum energy demand when treating low-sulphate UWW}

Figure 2 illustrates the energy requirements of the three schemes considered for designing an AnMBR-based WWTP treating low-sulphate UWW at 15 and $30^{\circ} \mathrm{C}$. Specifically, this figure shows the minimum energy requirements resulting from the corresponding optimum design values illustrated in Table 2.

As Figure 2 shows, the energy requirements of the WWTP slightly increase when including an additional anaerobic digestion step in the case of no methane capture. This is because of the addition of new mechanical equipment to the treatment scheme (e.g. stirrers for anaerobic digester). Nevertheless, these energy requirements are reduced when including a PS unit due to reducing the particulate organic matter entering the AnMBR unit, which allows decreasing MLSS in the anaerobic reactor. As a result, $Q_{\text {rec }}$ and HRT are reduced in the AnMBR unit in order to optimise $M L S S_{T M}$ (see Table 2). Moreover, lower optimal $M L S S_{T M}$ levels were reached in the PS+AnMBR+AD configuration, which allowed increasing the operating $J_{20}$ for a given $S G D_{m}$ due to meeting higher critical fluxes [22]. Thus, it is important to highlight that increasing $M L S S_{M T}$ raises filtration costs mainly due to decreasing the optimal operating $J_{20}$ (i.e. increasing membrane filtration area) for a given $S G D_{m}$, but decreases anaerobic reactor costs (mainly construction, stirring and sludge pumping costs). Hence, it is necessary to optimise the total AnMBR unit cost by optimising $M L S S_{M T}$ in order to meet optimum 
construction, stirring, sludge pumping and filtration costs [11].

Concerning the effect of operating temperature on power consumption, Figure 2 illustrates a reduction in the energy requirements of the different treatment schemes as the temperature increases. This reduction is attributed to an increase in the hydrolysis rate as temperature increases. Hence, lower optimal $M L S S_{T M}$ levels were reached at 30 ${ }^{\circ} \mathrm{C}$, which allowed, as previously commented, not only increasing $J_{20}$ but also decreasing $Q_{r e c}$ and HRT in the AnMBR unit.

As regards energy recovery from methane, Figure 2 shows that all the considered treatment schemes have significant potential to be net energy producers when treating low-sulphate UWW. Indeed, this figure shows that in case of capturing the methane it was possible to obtain surplus energy that could be exploited and/or sold, giving a maximum theoretical energy production of 0.08 and $0.12 \mathrm{kWh}$ per $\mathrm{m}^{3}$ when treating low-sulphate UWW at 15 and 30 ${ }^{\circ} \mathrm{C}$, respectively.

Figure 2 shows that $\mathrm{PS}+\mathrm{AnMBR}+\mathrm{AD}$ resulted in the lowest energy demand (energy surplus of $0.08 \mathrm{kWh}$ per $\mathrm{m}^{3}$ ) when treating low-sulphate UWW at $15^{\circ} \mathrm{C}$. Nevertheless, this behaviour was not reproduced when treating low-sulphate UWW at $30{ }^{\circ} \mathrm{C}$. When operating at $15^{\circ} \mathrm{C}$, the energy recovery potential of the plant was enhanced by increasing the amount of organic matter that was biodegraded in the AD unit at mesophilic temperature conditions. On the other hand, when operating at $30^{\circ} \mathrm{C}$ most of the influent organic matter was already biodegraded in the AnMBR at mesophilic temperature conditions, thus the addition of primary settling (i.e. PS+AnMBR+AD) did not significantly enhanced the energy recovery potential of the WWTP. Nevertheless, 
adding an additional anaerobic digestion step, AnMBR+AD, allowed improving somewhat the energy recovery potential of the WWTP (maximum theoretical energy production of $0.12 \mathrm{kWh}$ per $\mathrm{m}^{3}$ ) since the residual organic matter was biodegraded at 35 ${ }^{\circ} \mathrm{C}$ in the $\mathrm{AD}$ unit (against the temperature of $30^{\circ} \mathrm{C}$ of the AnMBR unit). In addition, the optimal SRT for the AD unit when treating low-sulphate UWW at $30^{\circ} \mathrm{C}$ was lower in AnMBR+AD than in PS+AnMBR+AD (see Table 2), which resulted in lower power requirements also due to a reduction in the stirring power consumption.

Nevertheless, the total cost of the different treatment schemes must be evaluated to determine the more feasible option when treating low-sulphate UWW at 15 and $30^{\circ} \mathrm{C}$.

\subsubsection{Minimum total cost when treating low-sulphate $U W W$}

Figure 3 illustrates the total cost of the three schemes considered for designing an AnMBR-based WWTP treating low-sulphate UWW at 15 and $30^{\circ} \mathrm{C}$. Specifically, this figure shows the minimum total cost resulting from the corresponding optimised values illustrated in Table 2.

As Figure 3 shows, no significant differences were detected in the total cost of the proposed treatment schemes for each of the evaluated scenarios. As regards the additional anaerobic digestion step, Figure 3 shows that adding an AD unit to the WWTP without including a primary settling step resulted in a slight increase of the total cost when treating low-sulphate UWW at 15 and $30{ }^{\circ} \mathrm{C}$. On the other hand, the total cost analysis revealed that the AnMBR scheme presented similar costs to $\mathrm{PS}+\mathrm{AnMBR}+\mathrm{AD}$ scheme mainly because of non-significant COD was consumed by SRB. Thus, most of the influent COD can be converted into methane in the AnMBR unit. Hence, AnMBR 
without primary settling and without further anaerobic digestion of the wasted sludge can be identified as the most feasible option for designing an AnMBR-based WWTP for low-sulphate UWW due to the following: 1) simplicity of the treatment scheme; and 2) reduced total cost.

\subsection{AnMBR-based WWTP treating high-sulphate $U W W$}

\subsubsection{Minimum energy demand when treating sulphate-rich $U W W$}

Figure 4 illustrates the energy requirements of the different schemes proposed for designing an AnMBR-based WWTP treating sulphate-rich UWW at 15 and $30{ }^{\circ} \mathrm{C}$. Specifically, this figure shows the minimum energy requirements resulting from the corresponding optimised values gathered in Table 2 .

As Figure 4 illustrates, the power requirements (in the case of not considering energy recovery from methane) of the AnMBR WWTP operating at $15^{\circ} \mathrm{C}$ can be reduced including an $\mathrm{AD}$ unit (AnMBR+AD scheme) and can be reduced even more including also the PS unit (PS+AnMBR+AD scheme). As previously commented, the optimal SRT for the AnMBR unit is decreased when AnMBR is combined with AD or PS and $\mathrm{AD}$ (see Table 2a). In these configurations (AnMBR+AD and PS+AnMBR+AD), shorter SRTs for the AnMBR were required since further degradation of the organic matter was conducted in the AD (there was no minimum SRT limitation in the AnMBR as regards sludge stabilisation). Hence, lower MLSS were reached in the AnMBR depending on HRT, which resulted in a reduction in the optimal design values (see Table 2). Similar results but in a lesser extent were obtained in the case of treating sulphate-rich UWW at $30^{\circ} \mathrm{C}$. 
Concerning energy recovery from methane, Figure 4 shows that it is possible to considerably reduce energy requirements in an AnMBR WWTP treating sulphate-rich UWW by including primary settling and further anaerobic digestion of the wasted sludge. Indeed, this figure shows that energy surplus could be achieved not only in the $\mathrm{PS}+\mathrm{AnMBR}+\mathrm{AD}$ configuration operating at 15 and $30^{\circ} \mathrm{C}$, but also in the AnMBR+AD configuration operating at $30^{\circ} \mathrm{C}$. However, it is important to highlight that the AnMBR unit is not used as a source of biogas when treating this sulphate-rich UWW. In these scenarios, the AnMBR unit aimed at meeting the effluent standards for COD/BOD since most of the influent COD was consumed by SRB. Therefore, the whole methane production came from the AD unit where the organic matter was biodegraded at $35^{\circ} \mathrm{C}$ by methanogenic microorganisms. Hence, the higher the amount of organic matter that is introduced to the AD unit the higher the energy recovery potential of the WWTP. In this respect, the $\mathrm{PS}+\mathrm{AnMBR}+\mathrm{AD}$ configuration resulted in the lowest power requirements due to the introduction of a fraction of the influent particulate organic matter directly to the AD system after settling in the PS unit, reducing therefore the amount of COD available in the AnMBR unit for sulphate reduction by SRB.

Nevertheless, the total cost of the different treatment schemes must be evaluated to determine the more economic option when treating sulphate-rich UWW at 15 and $30^{\circ} \mathrm{C}$.

\subsubsection{Minimum total cost when treating sulphate-rich $U W W$}

Figure 5 illustrates the total cost of the three schemes considered for designing an AnMBR-based WWTP treating sulphate-rich UWW at 15 and $30^{\circ} \mathrm{C}$. In particular, this figure shows the minimum total cost resulting from the corresponding optimised values 
illustrated in Table 2.

As Figure 5 shows, the cost of the AnMBR-based WWTP treating sulphate-rich UWW was significantly reduced by adding primary settling and anaerobic digestion of the wasted sludge. Hence, the total cost analysis revealed that PS+AnMBR+AD is, for this case study, the best option for treating sulphate-rich UWW since less COD is consumed by SRB, thus increasing the energy recovery potential of AnMBR technology. Specifically, cost savings of up to 40 and 50\% can be achieved by including an additional anaerobic digestion step and primary settling and additional anaerobic digestion step, respectively.

\subsection{Overall results}

Membrane area, anaerobic reactor construction and energy requirements remained the dominant contributors to total cost (representing around 30, 25 and 20-30\%, respectively), which are considered critical challenges to enable AnMBR to overtake activated sludge processes in practice. These results are in agreement with findings from other energy and cost assessments in the field (Smith et al., 2014; Lin et al. 2011; Ferrer et al. 2015). On the other hand, chemical reagent consumption and sludge handling and disposal accounted for up to 6 and $8 \%$ of total cost, respectively.

Table 3 summarises the total cost and the power requirements of the different AnMBR-based WWTP schemes evaluated at 15 and $30{ }^{\circ} \mathrm{C}$ for treating sulphate-rich and low-sulphate UWW. As this table shows, the total cost of an AnMBR WWTP is significantly lower when treating low-sulphate rather than sulphate-rich UWW (cost savings of up to $45 \%$ were estimated in this study). This demonstrates that, thanks to its 
very low costs, AnMBR technology is a feasible option for treating low/non sulphateloaded wastewaters.

It must also be highlighted that AnMBR has the potential to be a net energy producer when treating low-sulphate UWW. Table 3 shows that when methane is captured, it is possible to obtain surplus energy that can be exploited and/or sold, giving a maximum theoretical energy production of $0.12 \mathrm{kWh}$ per $\mathrm{m}^{3}$. Moreover, it is worth to point out that AnMBR combined with primary settling and anaerobic digestion of the wasted sludge has also the potential to be a net energy producer when treating sulphaterich UWW. In this case, it would be possible to achieve a maximum theoretical energy production of up to $0.09 \mathrm{kWh}$ per $\mathrm{m}^{3}$.

\section{Conclusions}

AnMBR without primary settling and without further anaerobic digestion of the wasted sludge was the most economic option (minimum cost of $€ 0.05$ per $\mathrm{m}^{3}$ ) for designing an AnMBR WWTP treating low-sulphate UWW at mild temperatures (above $15^{\circ} \mathrm{C}$ ). Indeed, when methane is captured, it is possible to obtain surplus energy of 0.1 $\mathrm{kWh}$ per $\mathrm{m}^{3}$. The combination PS+AnMBR+AD was the most economic option when treating sulphate-rich UWW (minimum cost of $€ 0.05$ per $\mathrm{m}^{3}$ ). The total cost of the AnMBR WWTP was significantly lower when treating low-sulphate rather than sulphate-rich UWW (cost savings of up to $45 \%$ can be met).

\section{Acknowledgements}


This research work was possible thanks to projects CTM2011-28595-C02-01/02 (funded by the Spanish Ministry of Economy and Competitiveness jointly with the European Regional Development Fund and Generalitat Valenciana GVAACOMP2013/203) and FCC Aqualia INNPRONTA IISIS IPT-20111023 (partially funded by the Centre for Industrial Technological Development (CDTI), and supported by the Spanish Ministry of Economy and Competitiveness).

\section{References}

[1] P.L. McCarty, J. Bae, J. Kim, Domestic wastewater treatment as a net energy producer-can this be achieved? Environ. Sci. Technol. 45 (2011) 7100-7106.

[2] H. Ozgun, R.K. Dereli, M.E. Ersahin, C. Kinaci, H. Spanjers, J.B. van Lier, A review of anaerobic membrane bioreactors for municipal wastewater treatment: Integration options, limitations and expectations, Sep. Purif. Technol. 118 (2012) 89-104.

[3] A.L. Smith, L.B. Stadler, N.G. Love, S.J. Skerlos, L. Raskin, Perspectives on anaerobic membrane bioreactor treatment of domestic wastewater: A critical review, Bioresource Technol. 122 (2012) 149159.

[4] H. Lin, W. Peng, M. Zhang, J. Chen, H. Huachang, Y. Zhang, A review on anaerobic membrane bioreactors: Applications, membrane fouling and future perspectives, Desalination 314 (2013) 169-188. [5] A. L, Smith, L.B. Stadler, L. Cao, N.G, Love, L. Raskin, S.J. Skerlos, 2014. Navigating Wastewater Energy Recovery 1 Strategies: A Life Cycle Comparison of Anaerobic Membrane Bioreactor and Conventional Treatment Systems with Anaerobic Digestion, Environ Sci. Technol. 48 (2914), 59725981.

[6] B. Lew, S. Tarre, M. Beliavski, C. Dosoretz, M. Green, Anaerobic membrane bioreactor (AnMBR) for domestic wastewater treatment, Desalination 243 (2009) 251-257.

[7] I. Martin, M. Pidou, A. Soares, S. Judd, B. Jefferson, Modelling the energy demands of aerobic and anaerobic membrane bioreactors for wastewater treatment, Environ. Technol. 32 (2011), 921-932.

[8] Z. Wang, J. Ma, C.Y. Tang, K. Kimura, Q. Wang, X. Han, Membrane cleaning in membrane bioreactors: A review. J. Membrane Sci. 468 (2014), 276-307.

[9] A. Robles, M.V Ruano, J. Ribes J. Ferrer, Advanced control system for optimal filtration in 
submerged anaerobic, J. Membrane Sci. 430 (2013), 330-341.

[10] A. Robles, M.V Ruano, J. Ribes, A. Seco, J. Ferrer, Model-based automatic tuning of a filtration control system for submerged anaerobic membrane bioreactors (AnMBR), J. Membrane Sci. 465 (2014) $14-26$.

[11] J. Ferrer, R. Pretel, F. Durán, J.B Giménez, A. Robles, M.V. Ruano, J. Serralta, J. Ribes, A. Seco, Design methodology for anaerobic membrane bioreactors (AnMBR): A case study, Sep. Purif. Technol. 141 (2015), 378-386.

[12] J. Ferrer, A. Seco, J. Serralta, J. Ribes, J. Manga, E. Asensi, J.J. Morenilla , F. Llavador, DESASS: A software tool for design, simulating and optimising WWTPs, Environ. Modell. Softw. 23 (2008) 19-26.

[13] J.B. Giménez, A. Robles, L. Carretero, F. Durán, M.V. Ruano, M.N. Gatti, J. Ribes, J. Ferrer, A. Seco, Experimental study of the anaerobic urban wastewater treatment in a submerged hollow-fibre membrane bioreactor at pilot scale, Bioresource Technol. 102 (2011) 8799 - 8806.

[14] A. Robles, M.V. Ruano, J. Ribes, J. Ferrer, Factors that affect the permeability of commercial hollow-fibre membranes in a submerged anaerobic MBR (HF-AnMBR) system, Water Res. 47 (2013) $1277-1288$.

[15] R. Pretel, A. Robles M.V. Ruano, A. Seco, J. Ferrer, The operating cost of an anaerobic membrane bioreactor (AnMBR) treating sulphate-rich urban wastewater, Sep. Purif. Technol. 126 (2014) $30-38$.

[16] R. Barat, J. Serralta, M.V. Ruano, E. Jiménez, J. Ribes, A. Seco, J. Ferrer, Biological nutrient removal model N 2 (BNRM2): a general model for wastewater treatment plants, Water Sci. Technol. 67 (2013) 1481-1489.

[17] F. Durán, Mathematical modelling of the anaerobic urban wastewater treatment including sulphatereducing bacteria. Application to an anaerobic membrane bioreactor (Modelación matemática del tratamiento anaerobio de aguas residuales urbanas incluyendo las bacterias sulfatorreductoras, Aplicación a un biorreactor anaerobio de membranas), Ph.D. thesis, Dept. of Hydraulic Engineering and Environment, Universitat Politècnica de València, Spain, 2013.

[18] J. Alex, L. Benedetti, J. Copp, J., K.V. Gernaey, U. Jeppsson, I. Nopens, M-N Pons., L. Rieger, C. Rosen, J.P Steyer, P. Vanrolleghem, S. Winkler, Benchmark Simulation Model no. 1 (BSM1). Dept. of Industrial Electrical Engineering and Automation Lund University, 2008.

[19] R. Pretel, A. Robles M.V. Ruano, A. Seco, J. Ferrer, Filtration process cost in anaerobic membrane 
bioreactors (AnMBRs) for urban wastewater treatment, Sep. Sci. Technol. (In press).

[20] M. Molinos-Senante, F. Hernández-Sancho, R. Sala-Garrido, M .Garrido-Baserba, Economic feasibility study for wastewater treatment: a cost-benefit analysis, Sci. Total Environ. 408 (2011), 953957.

[21] MAGRAMA. Official website of the Ministry of Agriculture, Food and Environment. Spanish government, Madrid. Avaiable on http://www.magrama.gob.es/es/calidad-y-evaluacionambiental/temas/prevencion-y-gestion-residuos/flujos/lodos-depuradora/ (acceded 21 may 2015). [22] A. Robles, M.V. Ruano, J. Ribes, J. Ferrer, Performance of industrial scale hollow-fibre membranes in a submerged anaerobic MBR (HF-SAnMBR) system at mesophilic and psychrophilic conditions, Sep. Purif. Technol. 104 (2013) 290-296.

[23] H. Lin, J. Chen, F. Wang, L. Ding, H. Hong, Feasibility evaluation of submerged anaerobic membrane bioreactor for municipal secondary wastewater treatment. Desalination 280 (2011) 120-126. 


\section{Figure and table captions}

Figure 1. Flow chart of the different schemes considered for designing an AnMBR-based WWTP: a) AnMBR; b) AnMBR+AD; c) PS+AnMBR+AD. PS: Primary settler; AnR: Anaerobic Reactor; MT:

Membrane Tank; DV: Degasification Vessel; AD: Anaerobic Digester; HE: Heat Exchanger; CIP: cleanin-place; and CHP: Combined Heat and Power.

Figure 2. Energy requirements of the three schemes considered for designing an AnMBR-based WWTP when treating low-sulphate UWW.

Figure 3. Total cost of the three schemes considered for designing an AnMBR-based WWTP when treating low-sulphate UWW.

Figure 4. Energy requirements of the three schemes considered for designing an AnMBR-based WWTP when treating sulphate-rich UWW.

Figure 5. Total cost of the three schemes considered for designing an AnMBR-based WWTP when treating sulphate-rich UWW.

Table 1. Characteristics of the wastewater entering the anaerobic reactor used for designing the proposed AnMBR WWTP ( ${ }^{*}$ sulphate-rich municipal wastewater; $\left.{ }^{* *} l o w-s u l p h a t e ~ m u n i c i p a l ~ w a s t e w a t e r\right)$.

Table 2. Optimum design values for the (a) AnMBR and (b) AD units included in the three schemes considered for designing an AnMBR-based WWTP.

Table 3. Optimum cost and energy requirements (considering energy recovery from methane) of the three schemes considered for designing an AnMBR-based WWTP at $15^{\circ} \mathrm{C}$ and $30^{\circ} \mathrm{C}$ when treating (a) lowsulphate and (b) sulphate-rich UWW. 


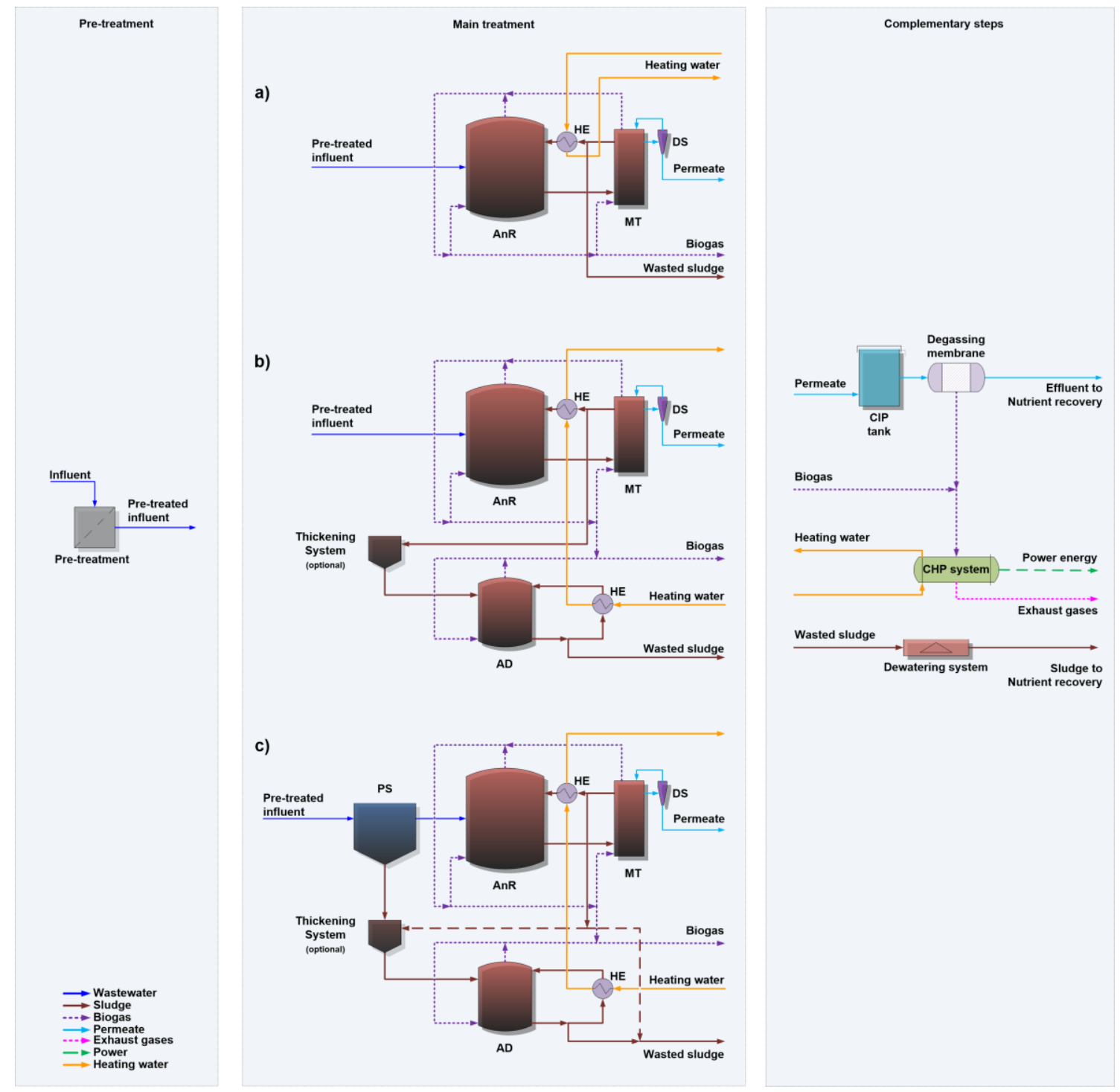

Figure 1. Flow chart of the different schemes considered for designing an AnMBR-based WWTP: a) AnMBR; b) AnMBR+AD; c) PS+AnMBR+AD. PS: Primary settler; AnR: Anaerobic Reactor; MT: Membrane Tank; DV: Degasification Vessel; AD: Anaerobic Digester; HE: Heat Exchanger; CIP: cleanin-place; and CHP: Combined Heat and Power. 


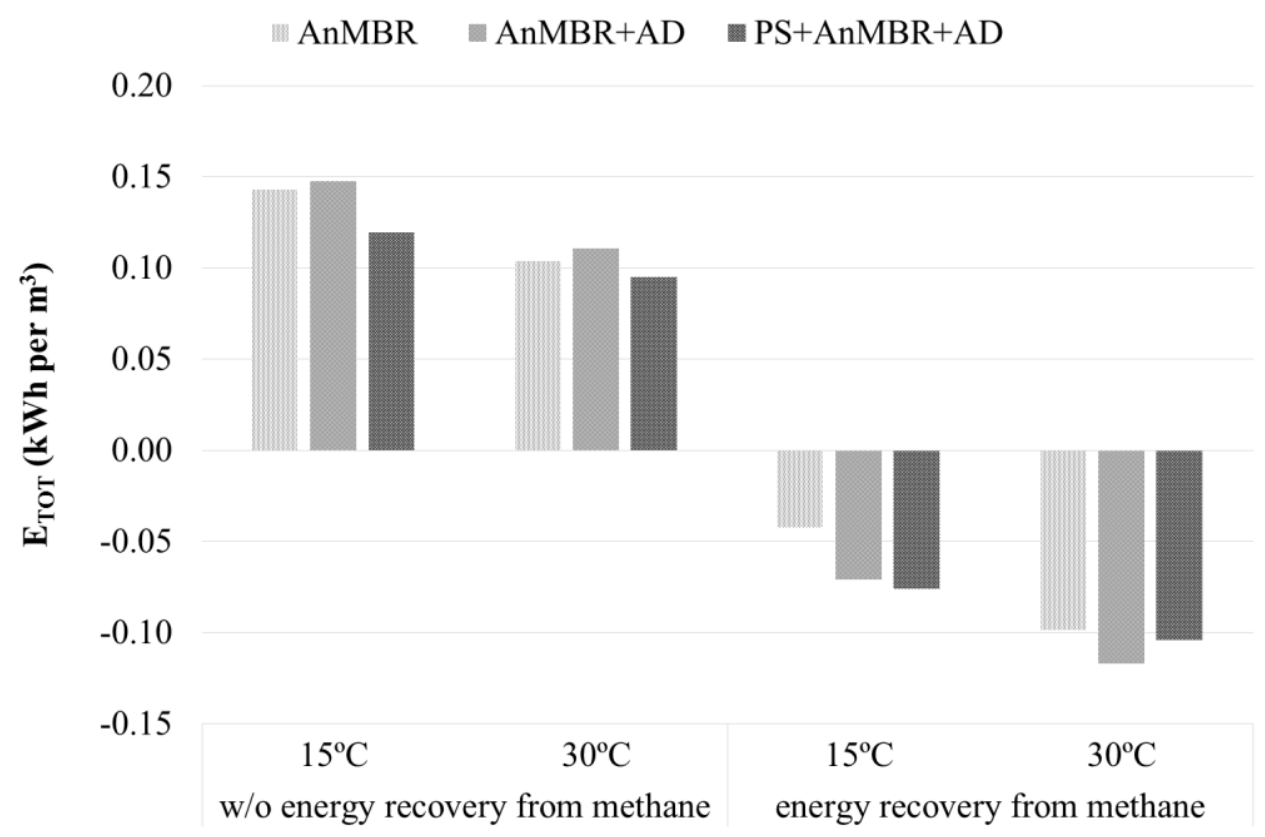

Figure 2. Energy requirements of the three schemes considered for designing an AnMBR-based WWTP when treating low-sulphate UWW. 
$=\mathrm{AnMBR}=\mathrm{AnMBR}+\mathrm{AD}=\mathrm{PS}+\mathrm{AnMBR}+\mathrm{AD}$

0.15

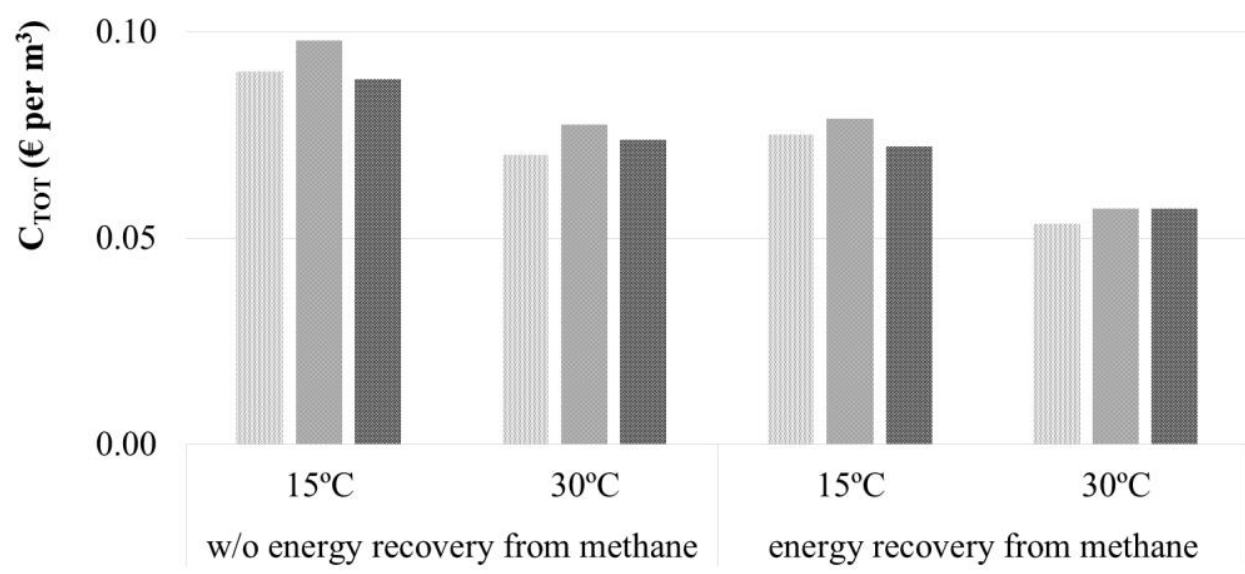

Figure 3. Total cost of the three schemes considered for designing an AnMBR-based WWTP when treating low-sulphate UWW. 


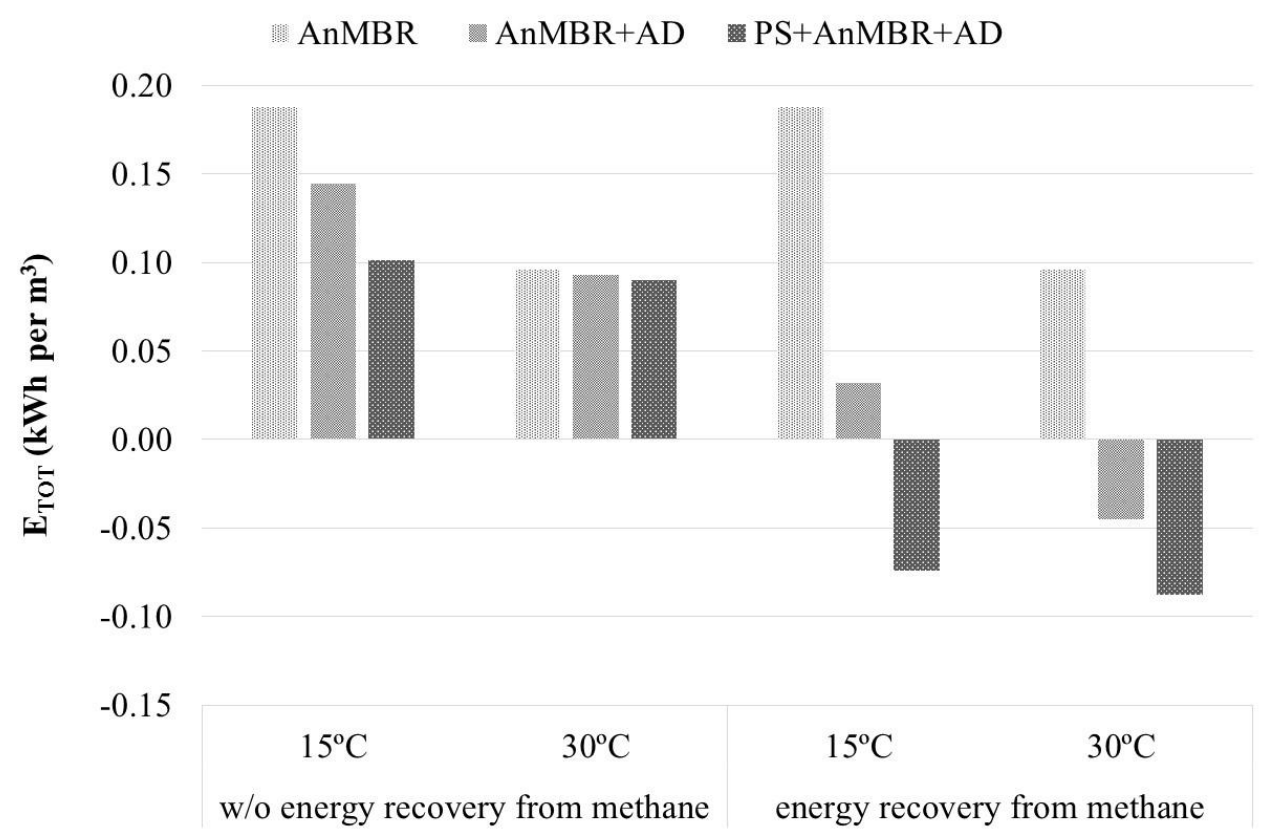

Figure 4. Energy requirements of the three schemes considered for designing an AnMBR-based WWTP when treating sulphate-rich UWW. 


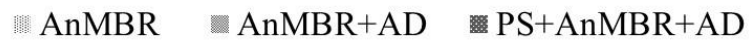
0.15

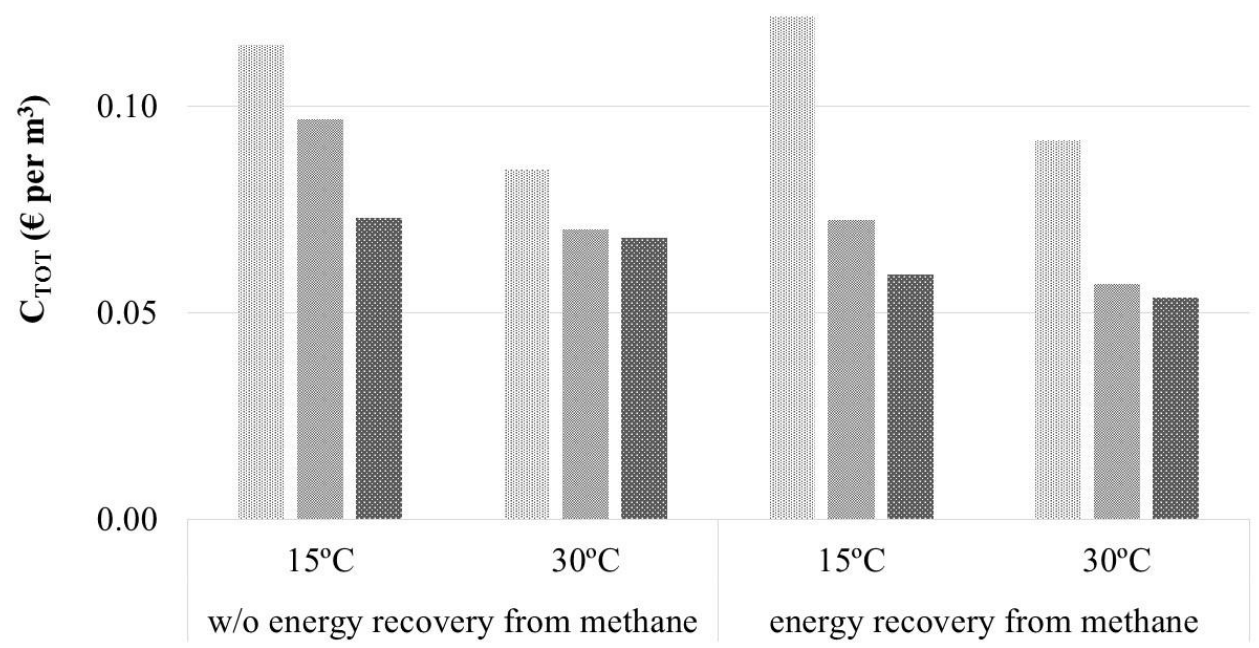

Figure 5. Total cost of the three schemes considered for designing an AnMBR-based WWTP when treating sulphate-rich UWW. 
Table 1. Characteristics of the wastewater entering the anaerobic reactor used for designing the proposed AnMBR WWTP ( ${ }^{*}$ sulphate-rich municipal wastewater; ${ }^{* *} l o w$-sulphate municipal wastewater).

\begin{tabular}{|c|c|c|}
\hline Parameter & Unit & Value \\
\hline TSS & $\mathrm{mg}$ TSS $\cdot \mathrm{L}^{-1}$ & 200 \\
\hline VSS & $\mathrm{mg} \mathrm{VSS} \cdot \mathrm{L}^{-1}$ & 160 \\
\hline T-COD & $\mathrm{mg} \mathrm{COD} \cdot \mathrm{L}^{-1}$ & 381 \\
\hline S-COD & $\mathrm{mg} \mathrm{COD} \cdot \mathrm{L}^{-1}$ & 99.5 \\
\hline $\mathrm{T}-\mathrm{BOD}_{20}$ & $\mathrm{mg} \mathrm{COD} \cdot \mathrm{L}^{-1}$ & 300 \\
\hline $\mathrm{S}-\mathrm{BOD}_{20}$ & $\mathrm{mg} \mathrm{COD} \cdot \mathrm{L}^{-1}$ & 69.5 \\
\hline VFA & $\mathrm{mg} \mathrm{COD} \cdot \mathrm{L}^{-1}$ & 10 \\
\hline $\mathrm{SO}_{4}-\mathrm{S}$ & $\mathrm{mg} \mathrm{S} \cdot \mathrm{L}^{-1}$ & $100 \% / 10^{* *}$ \\
\hline $\mathrm{TN}$ & $\mathrm{mg} \mathrm{N} \cdot \mathrm{L}^{-1}$ & 50 \\
\hline $\mathrm{NH}_{4}-\mathrm{N}$ & $\mathrm{mg} \mathrm{N} \cdot \mathrm{L}^{-1}$ & 31.5 \\
\hline $\mathrm{TP}$ & $\mathrm{mg} \mathrm{P} \cdot \mathrm{L}^{-1}$ & 6.9 \\
\hline $\mathrm{PO}_{4}-\mathrm{P}$ & $\mathrm{mg} \mathrm{P} \cdot \mathrm{L}^{-1}$ & 5 \\
\hline Alk & $\mathrm{mg} \mathrm{CaCO}{ }_{3} \cdot \mathrm{L}^{-1}$ & 350 \\
\hline $\mathrm{pH}$ & & 7 \\
\hline
\end{tabular}


Table 2. Optimum design values for the (a) AnMBR and (b) AD units included in the three schemes considered for designing an AnMBR-based WWTP when treating low-sulphate and sulphate-rich UWW.

\begin{tabular}{|c|c|c|c|c|c|c|c|c|c|c|c|c|}
\hline \multirow[b]{3}{*}{$\mathrm{T}\left({ }^{\circ} \mathrm{C}\right)$} & \multicolumn{4}{|c|}{$\begin{array}{c}\text { AnMBR } \\
\text { configuration }\end{array}$} & \multicolumn{4}{|c|}{$\begin{array}{l}\text { AnMBR+AD } \\
\text { configuration }\end{array}$} & \multicolumn{4}{|c|}{$\begin{array}{l}\mathrm{PS}+\mathrm{AnMBR}+\mathrm{AD} \\
\text { configuration }\end{array}$} \\
\hline & \multicolumn{2}{|c|}{$\begin{array}{c}\text { low-sulphate } \\
\text { UWW }\end{array}$} & \multicolumn{2}{|c|}{$\begin{array}{l}\text { sulphate-rich } \\
\text { UWW }\end{array}$} & \multicolumn{2}{|c|}{$\begin{array}{l}\text { low-sulphate } \\
\text { UWW }\end{array}$} & \multicolumn{2}{|c|}{$\begin{array}{l}\text { sulphate-rich } \\
\text { UWW }\end{array}$} & \multicolumn{2}{|c|}{$\begin{array}{l}\text { low-sulphate } \\
\text { UWW }\end{array}$} & \multicolumn{2}{|c|}{$\begin{array}{l}\text { sulphate-rich } \\
\text { UWW }\end{array}$} \\
\hline & 15 & 30 & 15 & 30 & 15 & 30 & 15 & 30 & 15 & 30 & 15 & 30 \\
\hline $\begin{array}{l}\text { SRT } \\
\text { (days) }\end{array}$ & 35 & 12 & 60 & 22 & 35 & 12 & 8 & 2 & 33 & 10 & 6 & 2 \\
\hline $\begin{array}{l}\text { HRT } \\
\text { (hours) }\end{array}$ & 14 & 7 & 23 & 10 & 14 & 8 & 9 & 4 & 10 & 4 & 6 & 3 \\
\hline $\begin{array}{l}Q_{\text {redinfluent }} \\
\quad \text { flow }\end{array}$ & 1.4 & 1.0 & 1.8 & 1.2 & 1.4 & 1.0 & 1.0 & 0.5 & 1.1 & 0.7 & 0.6 & 0.5 \\
\hline $\begin{array}{c}J_{20} \\
(\mathrm{LMH})\end{array}$ & 19 & 19 & 16 & 19 & 19 & 24 & 24 & 26 & 24 & 26 & 24 & 29 \\
\hline $\begin{array}{l}M L S S_{M T} \\
\left(\mathrm{~g} \cdot \mathrm{L}^{-1}\right)\end{array}$ & 15 & 10 & 18 & 15 & 15 & 10 & 10 & 8 & 10 & 8 & 10 & 5 \\
\hline $\begin{array}{c}S G D_{m} \\
\left(\mathrm{~m}^{3} \cdot \mathrm{m}^{-2} \cdot \mathrm{h}^{-1}\right)\end{array}$ & 0.1 & 0.1 & 0.1 & 0.1 & 0.1 & 0.1 & 0.1 & 0.1 & 0.1 & 0.1 & 0.1 & 0.1 \\
\hline
\end{tabular}

(a)

AnMBR+AD

$\mathrm{PS}+\mathrm{AnMBR}+\mathrm{AD}$

\begin{tabular}{ccccccccc} 
& low-sulphate UWW & \multicolumn{3}{c}{ sulphate-rich UWW } & low-sulphate UWW & \multicolumn{2}{c}{ sulphate-rich UWW } \\
\hline $\mathrm{T}\left({ }^{\circ} \mathrm{C}\right)$ & 15 & 30 & 15 & 30 & 15 & 30 & 15 & 30 \\
\hline $\begin{array}{c}\text { SRT } \\
(\text { days })\end{array}$ & 10 & 10 & 15 & 15 & 15 & 15 & 20 & 20 \\
$\begin{array}{c}M L S S_{A D} \\
\left(\mathrm{~g} \cdot \mathrm{L}^{-1}\right)\end{array}$ & 34 & 34 & 27 & 26 & 14 & 12 & 23 & 23 \\
\hline
\end{tabular}

(b) 
Table 3. Optimum cost and energy requirements (considering energy recovery from methane) of the three schemes considered for designing an AnMBR-based WWTP at $15^{\circ} \mathrm{C}$ and $30^{\circ} \mathrm{C}$ when treating (a) lowsulphate and (b) sulphate-rich UWW.

(a)

\begin{tabular}{|c|c|c|c|c|}
\hline & \multicolumn{2}{|c|}{$\begin{array}{l}\text { Total cost } \\
\left(€ \text { per } \mathrm{m}^{3}\right) \\
\end{array}$} & \multicolumn{2}{|c|}{$\begin{array}{c}\text { Energy requirements } \\
\left(\mathrm{kWh} \text { per } \mathrm{m}^{3}\right)\end{array}$} \\
\hline & $15^{\circ} \mathrm{C}$ & $30^{\circ} \mathrm{C}$ & $15^{\circ} \mathrm{C}$ & $30^{\circ} \mathrm{C}$ \\
\hline AnMBR configuration & 0.08 & 0.05 & -0.04 & -0.10 \\
\hline AnMBR+AD configuration & 0.08 & 0.06 & -0.06 & -0.12 \\
\hline PS $+A n M B R+A D$ configuration & 0.07 & 0.06 & -0.08 & -0.10 \\
\hline
\end{tabular}

(b)

\begin{tabular}{|c|c|c|c|c|}
\hline & \multicolumn{2}{|c|}{$\begin{array}{l}\text { Total cost } \\
\left(€ \text { per } \mathrm{m}^{3}\right) \\
\end{array}$} & \multicolumn{2}{|c|}{$\begin{array}{c}\text { Energy requirements } \\
\left(\mathrm{kWh} \text { per } \mathrm{m}^{3}\right)\end{array}$} \\
\hline & $15^{\circ} \mathrm{C}$ & $30^{\circ} \mathrm{C}$ & $15^{\circ} \mathrm{C}$ & $30^{\circ} \mathrm{C}$ \\
\hline AnMBR configuration & 0.12 & 0.09 & 0.19 & 0.09 \\
\hline AnMBR+AD configuration & 0.07 & 0.06 & 0.03 & -0.04 \\
\hline PS $+A n M B R+A D$ configuration & 0.06 & 0.05 & -0.07 & -0.09 \\
\hline
\end{tabular}

